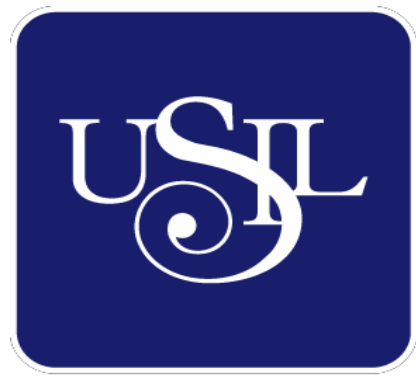

UNIVERSIDAD
SAN IGNACIO
DE LOYOLA

FACULTAD DE CIENCIAS EMPRESARIALES

Carrera de International Business

\title{
PROPUESTA DE IMPLEMENTACION DE UN PROCEDIMIENTO ESTANDARIZADO PARA MEJORAR LA GESTION DE IMPORTACIONES EN SYRSA SAC.
}

Tesis para optar el Título Profesional de Licenciado en International Business

CESAR DEYVIS LAGOS HUAMAN (0000-0002-6614-6227)

JUAN MANUEL MORA VALENZUELA (0000-0001-94495662)

Asesor:

Mg. Oscar Federico Muro Doig (0000-0002-5183-8327

Lima - Perú

2020 
"Los procesos son cómo las personas dentro de una organización colaboran con el fin de lograr un objetivo. En esencia todo lo que bacemos en una organización implica o contribuye a algún tipo de proceso". 


\section{Índice de Contenidos}

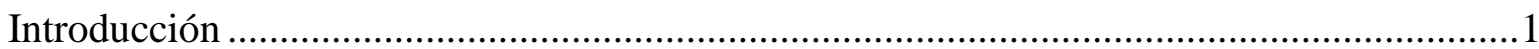

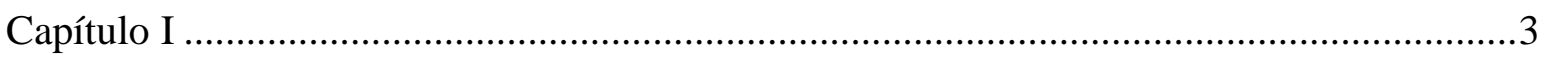

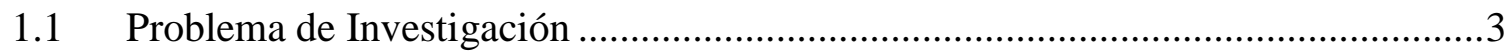

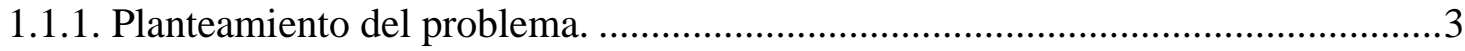

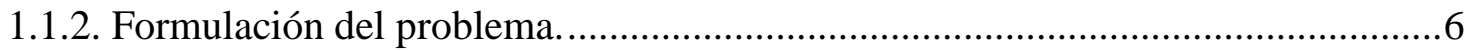

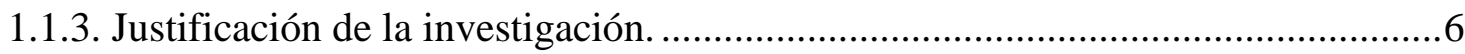

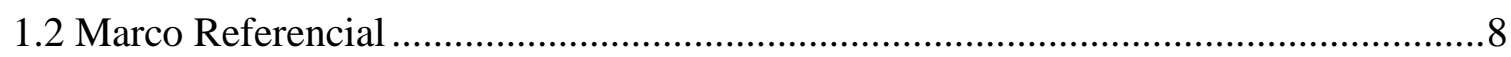

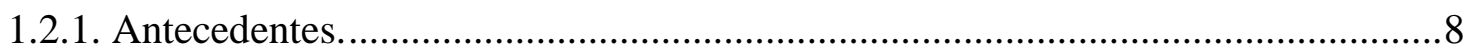

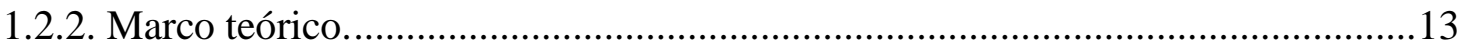

1.2.4. Definición de términos básicos........................................................................53

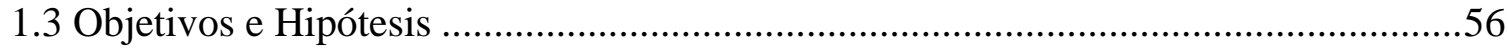

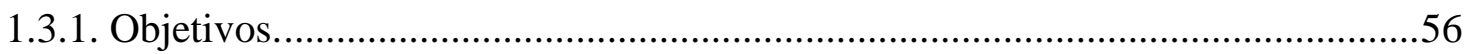

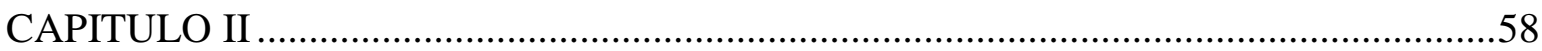

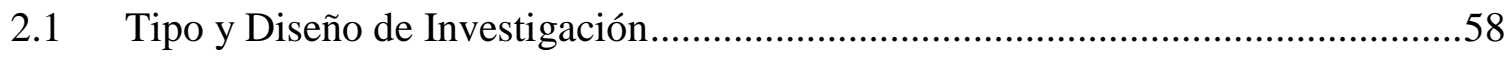

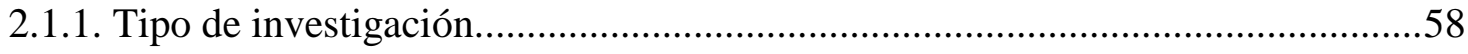

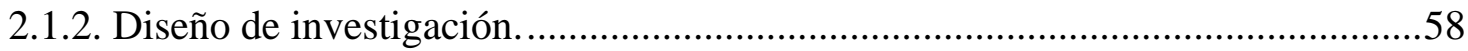

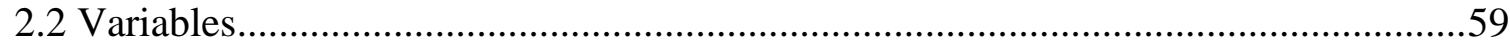

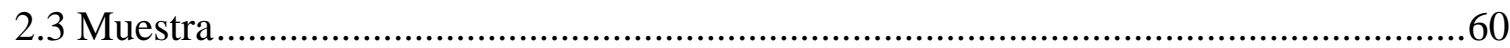

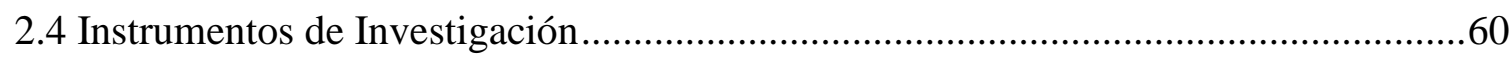

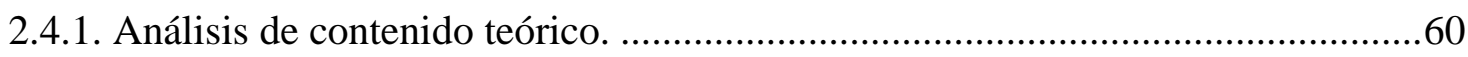

2.4.2. Análisis de contenido cuantitativo...................................................................60

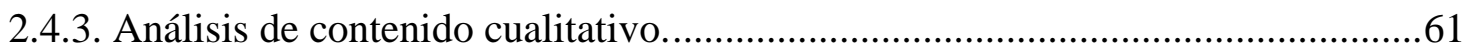

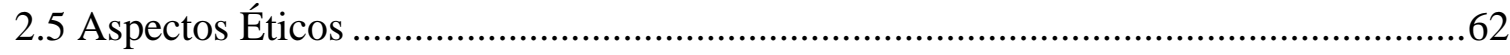

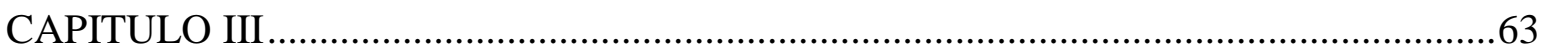

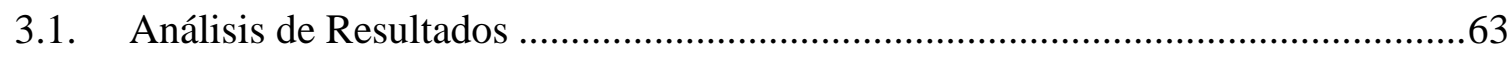

3.1.1. Análisis del desarrollo un procedimiento de actividades. ................................63

3.1.2. Análisis del tiempo de optimización del proceso logístico de importación. ........68

3.1.3. Análisis del costo de importación y las ventajas del comercio internacional. ...74

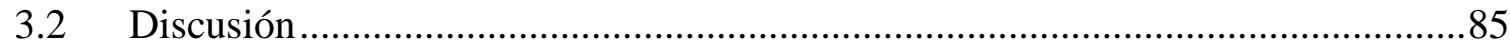

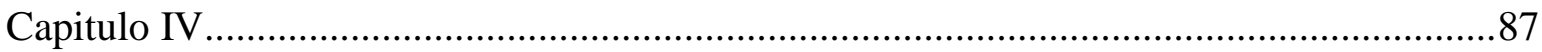

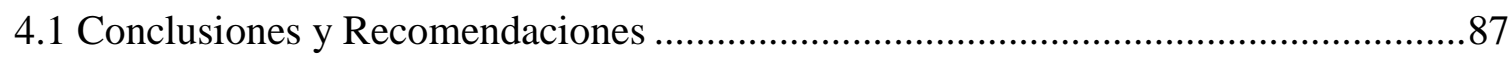

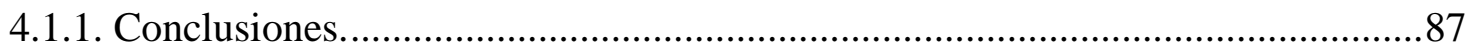




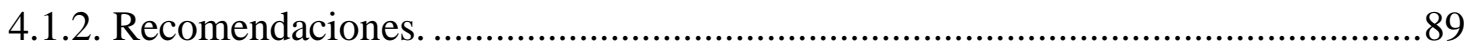

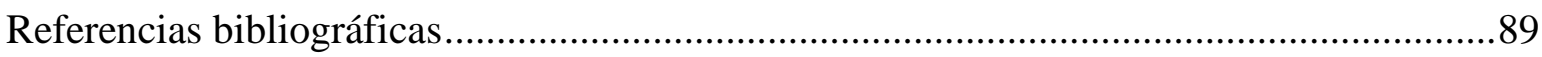

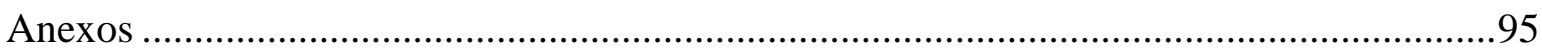

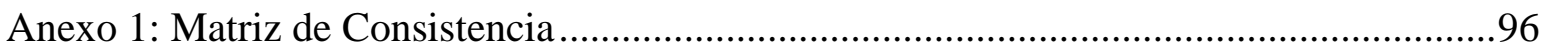

Anexo 2: Proceso Estandarizado de Importación de SYRSA SAC (Modelo propuesto) .....97

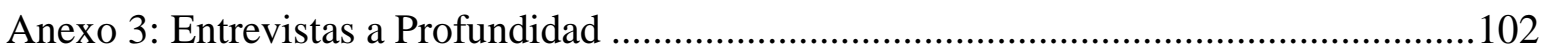

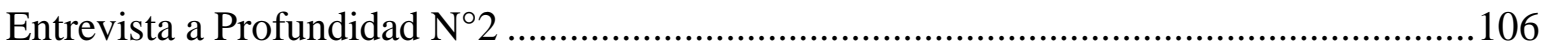

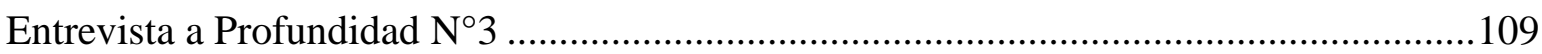

Anexo 4: Validación de instrumento de Medición .............................................................111

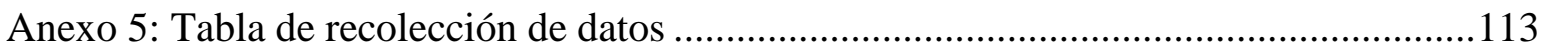




\section{Lista de Tablas}

Tabla 1. Derechos e Impuestos: tasa y base imponible ................................................45

Tabla 2. Tasa arancelaria ad valorem y sub partidas arancelarias .....................................45

Tabla 3. Actividades por puesto de trabajo de entrevistas ..................................................64

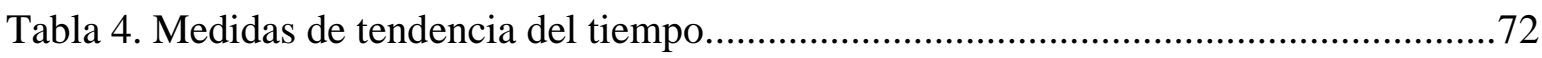

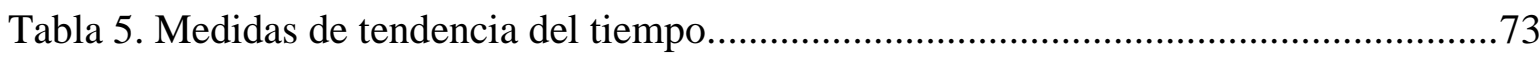

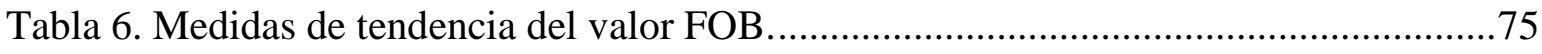

Tabla 7. Medidas de tendencia del valor CIF ….............................................................

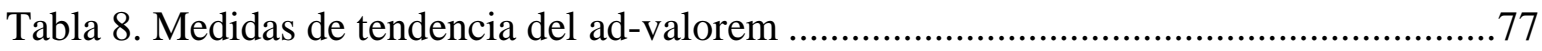

Tabla 9. Pago de ad valorem de las partidas arancelarias del embarque aéreo 43. .............82

Tabla 10. Diferencia entre pago y no pago de ad valorem en partidas arancelarias del

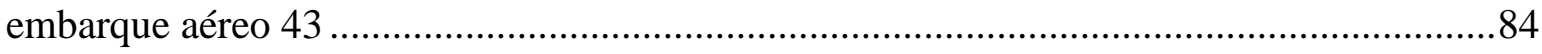




\section{Lista de Figuras}

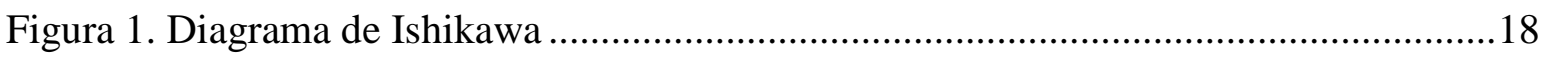

Figura 2. Diagrama de Ishikawa de las causas en de mora de gestión de importaciones.....67

Figura 3. Tiempo promedio de demora de los embarques aéreos........................................71

Figura 4. País de origen de los 66 embarques del 2019 .................................................73

Figura 5. Almacenes autorizados que utiliza la empresa ............................................ 74

Figura 6. Grafico del tiempo del monto FOB de los 66 embarques del 2019. Fuente:

Elaboración propia. .75

Figura 7. Grafico del tiempo del monto CIF de los 66 embarques del 2019. Fuente:

Elaboración propia .76

Figura 8. Grafico del gasto de aduana con y sin ad valorem de los 66 embarques del 2019.

Fuente: Elaboración propia . .77

Figura 9. Grafico del ad valorem de cada embarque aéreo en el 2019. .79

Figura 10. Gráfico de los números de serie con y sin ad-valorem de los 66 embarques aéreos del 2019. Fuente: Elaboración propia .79

Figura 11. Grafico del ad-valorem acumulado por país de los 66 embarques del 2019......80

Figura 12. Grafico del ad-valorem acumulado por país de los 66 embarques del 2019......81

Figura 13. Gráfico de la participación del ad-valorem sobre el costo unitario promedio de los 66 embarques del 2019. .82 